\title{
Editoriali
}

\section{Schizophrenia is (not simply) a neurodevelopmental disorder}

\author{
PAOLA DAZZAN and ROBIN M. MURRAY
}

Schizophrenia affects almost $1 \%$ of the population at some point in their life. It occurs in all geographic areas in which studies have been done, although the outcome appears to be better in developing countries. In this editorial we will discuss the evidence, from epidemiological, genetic and neuroimaging studies, that suggests that schizophrenia is in part a neurodevelopmental disorder. However, we will also point out that, contrary to some recent statements, this is not the whole story. Figure 1 provides a simplified view of our model.

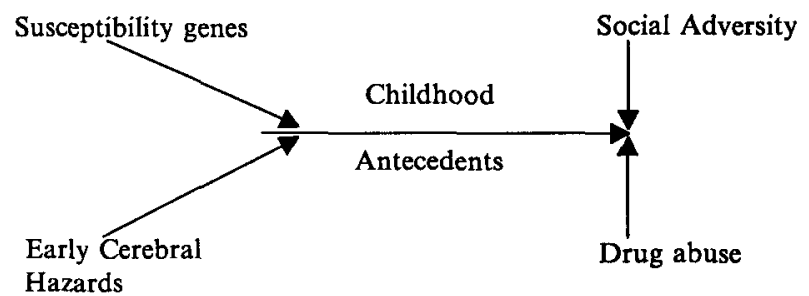

Figure 1. - A model for schizophrenia.

It is often said that the aetiology of schizophrenia is unknown; this is not true since a number of risk factors have been clearly established. These may be crudely divided into A) Biological predisposing fac-

Indirizzo per la corrispondenza: Dr. P. Dazzan, Institute of Psychiatry, Department of Psychological Medicine, De Crespigny Park, London SE5 8LT (UK).

Fax: + 44-171-701.9044

E-mail: spcbpad@iop.kcl.ac.uk tors which operate during development such as familial/genetic predisposition and early environmental insults, and B) Psychosocial precipitating factors which operate prior to the onset of illness such as social adversity and drug abuse.

\section{BIOLOGICAL PREDISPOSING FACTORS}

\section{What is the role of genes?}

The most powerful risk factor for developing schizophrenia is having an affected relative (Murray \& McGuffin, 1993). The risk of developing schizophrenia rises from $1 \%$ in the general population and $2 \%$ in the case of second degree relatives, to about $42 \%$ in the monozygotic co-twins of schizophrenics (Cardno et al., 1999). Further evidence of a role for genes comes from studies of the unaffected relatives of schizophrenic subjects. Sharma et al. (1998) have shown that in families where several members are affected by schizophrenia, the unaffected relatives who appear to be transmitting the disorder show enlarged ventricles, similar to their affected relative. Indeed, the unaffected relatives in such families show a range of minor abnormalities in tests of neuropsychology, eye tracking, neurological signs, and event-related potentials, as well as an excess of mixed handedness. Thus, they appear to show in minor form many of the abnormalities found in schizophrenic subjects (Wickham \& Murray, 1997).

There have been many studies applying molecular genetic techniques to schizophrenia in recent years. 
Much of this research has been conducted on multiply affected pedigrees, using a technique known as linkage analysis (the use of a known genetic marker to locate the faulty gene). Attention has recently focused on the chromosomes $6,22,13$, and more recently 8 , but the results have been inconclusive (Gill et al., 1996; Straub et al., 1995). Various candidate genes such as those involved in the dopamine pathway have also been studied but again with contradictory findings. We can conclude that if a major gene existed which explained a large proportion of the variance in liability to schizophrenia, it would have been found by now. It seems more likely that a number of genes of relatively small effect are necessary (Maier \& Schwab, 1998)

So, are genes the only cause? It seems not! The concordance between monozygotic twins is less than $50 \%$ which suggests the action of some environmental factors.

But which environmental factors?

\section{Doomed from the womb?}

Obstetric complications (OCs) have been repeatedly shown to be a risk factor for developing schizophrenia, with an odds ratio of about 2 for OCs in general (McNeil, 1995; McGrath \& Murray, 1995). Attention has focused on those complications associated with a risk of hypoxic-ischaemic brain damage (Verdoux et al., 1997), as one of the possible causes for the ventricular enlargement observed in schizophrenic patients (Murray et al., 1985). Also, the reduced hippocampal size observed (Suddath et al., 1990) in schizophrenia has been related to the presence of OCs of the types associated with hypoxia-hyschaemia (Stefanis et al., 1999).

Some authors have contended that OCs could just be the consequence of an earlier impairment of brain growth, as suggested by a reduced birth weight (Rifkin et al., 1994) and smaller head circumference observed in these patients. Another evidence suggesting the operation of some earlier factor is the tendency for schizophrenic subjects to be born in late winter and spring (Torrey et al., 1997); this could be secondary to subtle brain damage in the foetus due to winter viral infection. This has been supported by an association between maternal fever in the latter part of pregnancy and later schizophrenia (Jones et al., 1998). There has been a heated controversy over reports of an increased number of children who later developed schizophrenia born several months after influenza epidemics (Sham et al., 1992; Kunugi et al., 1995). Others have suggested that exposure to rubella or polio or to maternal malnutrition could all increase the risk of later schizophrenia.

A parsimonious way of making sense of the numerous reports of prenatal risk factors is that a range of illnesses in the mother may slightly impair the cortical development of her baby, and that this in turn increases the risk of later schizophrenia. It is probable also that cerebral insults and infections in early childhood increase the risk (Cannon \& Murray, 1998)

\section{A lonely childhood?}

Longitudinal cohort studies and studies of highrisk children have all reported an excess of minor social and cognitive deficits pre-dating the onset of the schizophrenic illness. Children destined to develop schizophrenia show deficits in attention, in visuoperceptual tests and in language acquisition. They are more likely to show delayed neuro-motor development, including retarded skeletal growth. Even as early as age 4 , they tend to be more likely to play alone and, during adolescence, they show a lack of confidence and tendency to social withdrawal and anhedonia (Jones et al., 1994; Cannon et al., 1999).

These premorbid changes are seen by many as the expression of the same underlying brain abnormality which will later produce frank psychosis. However, this is not proven, and it is also possible these childhood characteristics act as independent risk factors. Such a model would suggest that preschizophrenic individuals proceed on a course of increasing deviance with an accumulation of risk factors pushing them towards the threshold for the development of frank psychosis (figure 2).

\begin{tabular}{llc}
\hline Category & Specific & Effect Size \\
\hline Genetic* $^{*}$ & MZ Twin & 45 \\
Early Environmental $^{1}$ & DZ Twin or Sibling & 5 \\
& Obstetric Complications & 2 \\
& Maternal Infection & 2 \\
& City birth & 1.4 \\
& Late-winter/Spring birth & 1.1 \\
Late Environmental $^{1}$ & Immigrant status & 4 \\
& Chronic Cannabis Abuse & 2 \\
& Adverse Life Events & 1.5 \\
\hline
\end{tabular}

* Relative Risk, ' Odds Ratios

Figure 2. - Risk factors for schizophrenia (from Cannon \& Jones, 1996). 
Hand preference is an index of functional lateralization which has been repeatedly studied in schizophrenic subjects. An excess of non-right handedness (ambiguous handedness or ambidexterity) (Cannon et al., 1995), but not of pure left-handedness, has been reported in schizophrenic subjects. Ambiguous handedness has also been observed in pre-schizophrenic children (Crow et al., 1996), in people who score highly on measures of psychosis proneness and in subjects with schizotypal traits (Chapman \& Chapman, 1987; Kim et al., 1992). It has also been reported in a variety of neurodevelopmental disorders as dyslexia, mental retardation and autism (Orr et al., in press).

In general, right-handed subjects have a more asymmetrical brain than those who are left or mixed-handed. The excess of mixed handedness in patients with schizophrenia may correspond to the lack of hemispheric asymmetry observed in their brains. Crow (1997) proposes that this loss of normal asymmetry is genetic. According to his theory, mixed-handedness would reflect a less completely lateralised pattern and should be found in excess also among the unaffected relatives of schizophrenic subjects. In support of this hypothesis is the finding of an abnormal hemispheric asymmetry not only in schizophrenic patients from families with several affected members, but also in those healthy relatives who appear to be transmitting the disorder (Sharma et al., in press).

\section{Is it better to be female?}

Schizophrenia affects both sexes but much recent research suggests that severe schizophrenia is more common in males (Castle et al., 1993). There is also a different age-of-onset with male subjects presenting, on average, approximately five years before female subjects. The difference in age of onset between male and female subjects disappears when the patients come from families multiply affected with the disorder (that is heavily genetically loaded). This observation suggests a role for environmental factors in bringing forward the age of onset in males.

Onset is not the only difference between the two sexes. Female schizophrenics are in general more advantaged. They show better premorbid functioning, better social adjustment, and better outcome (i.e., a more schizoaffective picture) (Foerster et al., 1991a, b). Some studies suggest that they also show less structural abnormalities than male subjects. Males are at increased risk of neurological and neuropsychological damage than their female counterpart (Castle \& Murray, 1991). Murray (1994), observing that neurodevelopmental disorders such as autism, dyslexia, conduct disorder and hyperactivity are more common in males, postulates that the early onset observed in male could be the consequence of a greater vulnerability of the developing male brain to environmental insult.

In a comparison of MRI images from schizophrenics and normals, matched for gender and handedness, it was observed that only male schizophrenics showed a reversed hemispheric asymmetry (Bullmore et al., 1995). This is particularly interesting considering that males are generally more severely affected by the illness and show more pronounced structural abnormalities. It is intriguing to suggest that left-sided damage during brain development is more characteristic of male subjects and that the neurobehavioral asymmetries correspond to the neuroanatomical structure.

\section{A DYSPLASTIC NETWORK DISORDER}

\section{What does the brain look like?}

It seems likely that in some cases at least, the process that characterises schizophrenia starts early in the life of the individual.

Some support for a neurodevelopmental disturbance starts from the suggestion of an abnormal migration of neurons in utero, with a greater number of neurones in the deep layers than in the more superficial ones in the cortex of schizophrenic subjects. At a more macroscopic level, the presence of subtle abnormalities in the brain structure of schizophrenic subjects - enlarged ventricular size, decrease in the volumes of cortex, temporal lobe and hippocampus, and abnormal hemispheric asymmetry - may also have a developmental origin (Suddath et al., 1990).

A possible anomaly in the development of hemispheric asymmetry has also been studied. Normally, the cerebral hemispheres start growing asymmetrically in utero, and by the second trimester of intrauterine life the hemispheric asymmetry is already recognisable. The asymmetry consists of right $>$ left prefrontal, premotor and temporal volumes, and left $>$ than-right occipito-parietal and sensorimotor volumes. In patients with schizophrenia, this 
hemispheric asymmetry has been described as reduced (hemispheres more symmetrical) or simply reversed (Luchins et al., 1979; 1982; Bilder et al., 1994). This lack or reversal provides further evidence of a neurodevelopmental aetiology of schizophrenia.

Given the disorders'of speech observed in schizophrenia, much interest has focused on the shape and size of the Planum Temporale (PT). The PT is an area on the superior surface of the superior temporal gyrus (STG) of the temporal lobe and it is involved in language comprehension and, to a lesser extent, production. This area has been reported to show a natural leftward (i.e., left $>$ right) asymmetry (Geschwind \& Levitsky, 1968) in most right and left-handed subjects. Although it has been suggested that this asymmetry is lost or reversed in schizophrenic patients, other studies have not shown this. Barta et al. (1990) observed a reversed asymmetry of the surface of the PT (right $>$ left), but this asymmetry did not correspond to a reversal of its volume. In a recent metanalysis, Shaplenske et al. (1999) remarked that the PT gross anatomical boundaries remain in dispute and the methods of measurements of the PT in different studies lack comparability. They conclude that the PT shows a leftward asymmetry in normals, reduced in left handed and females, and that this asymmetry appears reduced in schizophrenic subjects due to a relatively larger right PT than normal controls.

\section{Loss of connectivity?}

Patients suffering from schizophrenia show a diffuse but subtle impairment of neuropsychological tasks, similar to that of mildly brain damaged patients. These deficits are already present in first-episode, never-medicated schizophrenic subjects (Saykin et al., 1994). From an extensive review of the literature, Saykin et al. (1991) conclude that schizophrenia is associated with deficits in verbal memory, learning, attention, abstraction and visuo-motor processing.

Using modern imaging techniques, the pattern of cerebral blood flow (a proxy for neuronal activity) during the performance of a specific task or the occurrence of a specific symptom has been studied. Studies on task-activated blood flow in schizophrenic subjects show a reduced blood flow in the frontal lobes (hypofrontality) during tests of frontal lobe function as the Wiscounsin Card Sorting Test. Studies of brain activation during the execution of ver- bal fluency tasks (Frith et al., 1995) have shown that in schizophrenic subjects the left dorsolateral prefrontal cortex is activated though perhaps to a lesser extent than in normal subjects. However, schizophrenic subjects show a failure of the normal suppression of activation of the left superior temporal cortex during this task. This is thought to reflect loss of the normal connectivity between the frontal and temporal cortex.

\begin{tabular}{cc}
$\begin{array}{c}\text { Difficulty in making accurate } \\
\text { inferences about other } \\
\text { children's mental states } \\
\downarrow\end{array}$ & $\begin{array}{c}\text { "Theory of Mind" } \\
\text { Difficulties }\end{array}$ \\
$\begin{array}{c}\text { Increasingly unsure of self, } \\
\text { leading to social withdrawal } \\
\downarrow\end{array}$ & SOCIAL ISOLATION \\
$\begin{array}{c}\downarrow \\
\text { Decreasing opportunities }\end{array}$ & PARANOID STYLE \\
for social interaction and reality testing & OF THINKING \\
\hline
\end{tabular}

Figure 3. - Self-perpetuating cascade of abnormal function (Jones et al., 1994).

\section{Which hand?}

Studies on symptoms have focused on auditory hallucinations. The presence of auditory hallucinations is associated with increased cerebral blood flow in the left frontal and temporal lobes (Gur \& Pearlson, 1993). In a study by McGuire et al. (1993), patients experiencing auditory hallucinations showed increased blood flow in Broca's area, an area involved in the production of words. It was therefore suggested that hallucinations could represent the patient's misinterpretation of his own inner speech, and that this could arise because of loss of the normal fronto-temporal connectivity, i.e. between the areas concerned with the «inner voice» and those concerned with the «inner ear».

\section{PSYCHOSOCIAL PRECIPITATING FACTORS}

\section{Living in the city}

The prevalence of schizophrenia is higher in urban than in rural areas (Torrey \& Bowler, 1990). It used to be thought that this was explained by selective migration of preschizophrenic subjects from rural to urban areas before the onset of the illness. However, it has been recently observed in several studies (Lewis et al., 1992; Mortensen et al., 1999) 
that the risk appears higher in people born or brought up in urban areas, independently from their place of residence. This is not a universal finding and it is not clear what the causes of this are. Possible candidates include overcrowding which could facilitate the spread of infections, and increased exposure to drug abuse or paradoxically to social isolation.

\begin{abstract}
Abusing drugs
Comorbidity between schizophrenia and substance abuse is common, and in particular, cannabis is commonly used, by schizophrenic subjects. The reason for this association is not totally clear. However, there is some evidence that the heavy consumption of Cannabis is associated with an increased risk of psychosis (Andreason et al., 1987), and that cannabis could actually precipitate a psychotic illness in subjects genetically predisposed to the illness (McGuire et al., 1994).
\end{abstract}

\section{Being an immigrant}

The incidence of schizophrenia has been historically reported as increased in groups of immigrants. An initial explanation was the misdiagnosis by local psychiatrists or the cultural intolerance of the host country. Other possible explanations have included the selective migration of predisposed individuals, the role played by the stress of leaving one's own country, and the difficulties in adapting to a different culture (McKenzie \& Murray, submitted for publication). Much interest has focused on the high rates of schizophrenia observed in the African-Caribbean population in the United Kingdom (Wessely et al., 1991). This is in contrast with the rates in the Caribbean, which are comparable to those in the white UK population (Bhugra et al., 1997). Most interestingly, the rates are especially increased in the siblings of the second generation suggesting the operation of some environmental factor(s) not present in the Caribbean.

\section{And suffering life events}

An excess of life events has been observed in schizophrenic subjects in the 3 weeks preceding the onset or a relapse of the illness, when compared to controls subjects (Bebbington et al., 1993). Some suggest that the excess of life events could constitute an effect of the illness rather than a cause of it (i.e., the event could be the consequence of the abnormal behavior exhibited in a prodromal phase of the illness or in the initial phase of an incoming relapse. Alternatively, and more probably in our view, social adversity might precipitate psychosis in those already predisposed individuals.

\section{CONCLUSION}

There is increasing dissatisfaction with the concept of schizophrenia but little agreement on how to replace it. One historical alternative to the traditional Kraepelinian concept is to apply the «Bonhoeffer paradigm» to schizophrenia. This postulates that identical or similar clinical pictures do not necessarily share the same aetiology and that their course and outcome may be completely different from each other.

In schizophrenia, the presence of similarity in the core Schneiderian symptoms is inevitable, given that such symptoms are necessary for the diagnosis to be made. But such symptoms do not describe the whole picture. A number of recent studies have suggested that a number of other features tend to occur together in two major constellations. On one side, we find male sex, obstetric complications, childhood cognitive and behavioral abnormalities, early onset, neuroanatomical abnormalities and worse outcome. On the other side, we see a different constellation: female sex, later onset of illness, good premorbid and interepisodic functioning, and almost unremarkable brain structure. The first constellation has been said to reflect neurodevelopmental impairment (Castle et al., 1994) and a possible association with language deficits and a less asymmetric brain is currently investigated. The second constellation certainly appear to be similar to the clinical picture of the affective psychosis.

Do these differences reflect different illnesses or do they represent different dimensions of psychosis? They certainly appear to reflect the operation of different aetiological factors, i.e. a) neurodevelopmental and b) affective-socially reactive respectively. Murray et al (1992) suggested the existence of two discrete illnesses, both exhibiting Schneiderian first rank symptoms but such a classification was found no better than the traditional Kraepelinian dichotomy, since there appeared to exist many cases in which both factors were operating. Therefore, more 
recently, Murray and colleagues (Van Os et al., 1998; submitted for publication) have postulated a dimensional model in which neurodevelopmental impairment is most prominent at the severe «chronic schizophrenic» pole and the affective-reactive factor at the other, «manic-depressive» pole. Such an interpretation allows for many mixed cases.

\section{REFERENCES}

Andreasson S., Allebeck P., Engstrom A. \& Rydberg, U. (1987). Cannabis and schizophrenia: a longitudinal study of Swedish conscripts. Lancet ii, 1483-1485.

Barta P.E., Pearlson G.D., Powers R.E., Richards S.S. \& Tune L.E. (1990). Auditory hallucinations and smaller superior temporal gyral volume in schizophrenia. American Journal of Psychiatry $147,1457-1462$.

Bebbington P.E., Wilkins S., Jones P., Foerster A., Murray R., Toone B. \& Lewis S. (1993). Life events and psychosis: Initial results from the Camberwell Collaborative Psychosis Study. British Journal of Psychiatry 162, 72-79.

Bhugra D., Leff J., Mallett R., Der G., Corridan B. \& Rudge S. (1997). Incidence and outcome of schizophrenia in whites, African-Caribbean and Asians in London. Psychological Medicine 27, 791-798.

Bilder R.M., Wu H., Bogerts B., Degreef G., Ashtari M., Alvir J.M.J., Snyder P.J. \& Lieberman J.A. (1994). Absence of regional hemispheric volume asymmetries in first episode schizophrenia. American Journal of Psychiatry 151, 1437-1447.

Bullmore E.T., Brammer M.J., Harvey I., Murray R. \& Ron M. (1995). Cerebral hemispheric asymmetry revisited: effects of gender, handedness and schizophrenia measured by radius of gyration in magnetic resonance images. Psychological Medicine $25,349-363$.

Cannon M. \& Jones P. (1996). Schizophrenia: neuroepidemiology review series. Journal of Neurology Neurosurgery and Psychiatry 61, 604-613.

Cannon M. \& Murray R.M. (1998). Neonatal origins of schizophrenia. Archives of Disease in Child 78, 1-3.

Cannon M., Byrne M., Cassidy B., Larkin C., Horgan R., Sheppard N.P. \& O'Callaghan E. (1995). Prevalence and correlates of mixed-handedness in schizophrenia. Psychiatry Research 59, 119-125.

Cannon M., Jones P., Huttunen M.O., Tanskanen A., Huttunen T., Rabe-Hesketh S. \& Murray R.M. (1999). School performance in Finnish children and later development of schizophrenia. Archives of General Psychiatry 56, 457-463.

Cardno A.G., Marshall J.E., Coid B., Macdonald A.M., Ribchester T.R., Davies N.J., Venturi P., Jones L.A., Lewis S.W., Sham P.C., Gottesman I.I., Farmer A.E., McGuffin P., Reveley A.M. \& Murray R.M. (1999). Heritability estimates for psychotic disorders: The Maudsley Twin psychosis series. Archives of General Psychiatry 56, 162-168.

Castle D.J. \& Murray R.M. (1991). The neurodevelopmental basis of sex differences in schizophrenia. Psychological Medicine 21, 565-575.

Castle D.J., Wessely S. \& Murray R.M. (1993). Sex and schizophrenia: effects of diagnostic stringency, and associations with premorbid variables. British Journal of Psychiatry 162, 658664.
Castle D.J., Sham P.C., Wessely S. \& Murray R.M. (1994). The subtyping of schizophrenia in men and women: a latent class analysis. Psychological Medicine 24, 41-51.

Chapman J.P. \& Chapman L.J. (1987). Handedness of hypothetically psychosis prone subjects. Journal of Abnormal Psychology 96, 89-93.

Crow T.J. (1997). Is schizophrenia the price that Homo Sapiens pays for language? Schizophrenia Research 28, 127-141.

Crow T.J., Done D.J. \& Sacker A. (1996). Cerebral lateralization is delayed in children who later develop schizophrenia. Schizoprenia Research 22,181-185.

Foerster A., Lewis S., Owen M.J. \& Murray R.M. (1991a). Premorbid personality in psychosis: effects of sex and diagnosis. British Journal of Psychiatry 158, 171-176.

Foerster A., Lewis S.,Owen M.J. \& Murray R.M. (1991b). Low birth weight and a family history of schizophrenia predict poor premorbid functioning in psychosis. Schizophrenia Research 5, 3-20.

Frith C.D., Friston K.J., Herold S., Silbersweig D., Fletcher P., Cahill C., Dolan R.J., Frackowiak R.S.J. \& Liddle P.F. (1995). Regional brain activity in chronic schizophrenic patients during the performance of a verbal fluency task. British Journal of Psychiatry 167, 343-349.

Geschwind N. \& Levitsky, W. (1968). Human brain: left-right asymmetries in temporal speech region. Science 161, 186-187.

Gill M., Vallada H., Collier D., Sham P., Holmans P., Murray R., McGuffin P., Nanko S., Owen M., Antonarakis S., Housman D., Kazazian H., Nestadt G., Pulver A.E., Straub R.E., MacLean C.J., Walsh D., Kendler K.S., DeLisi. L., et al. (1996). A combined analysis of D22S278 marker alleles in affected sib-pairs: support for a susceptibility locus for schizophrenia at chromosome 22q12. Neuropsychiatric Genetics 67, 4045.

Gur R.E. \& Pearlson G. (1993). Neuroimaging in schizophrenia research. Schizophrenia Bulletin 19, 337-353.

Jones P., Rodgers B., Murray R.M. \& Marmot M. (1994). Child development risk factors for adult schizophrenia in the British 1946 birth cohort. Lancet 344, 1398-1402.

Jones P.B., Rantakallio P., Hartikainen A.L., Isohanni M. \& Sipila P. (1998). Schizophrenia as a long-term outcome of pregnancy, delivery, and perinatal complications: a 28-year follow-up of the 1966 North Finland general population birth cohort. American Journal of Psychiatry 155, 355-364.

Kim D., Rainè A., Triphon N. \& Green M.F. (1992). Mixed-handedness and features of schizotypal personality in a non-clinical sample. Journal of Nervous and Mental Disease 180, 133135.

Kunugi H., Nanko S., Takei N., Saito K., Hayashi N. \& Kazamatsuri H. (1995). Schizophrenia following in utero exposure to the 1957 influenza epidemics in Japan. American Journal of Psychiatry 152, 106-107.

Lewis G., David A., Andreasson S. \& Allebeck P. (1992). Schizophrenia and city life. Lancet 340, 137-140.

Luchins D.J., Weinberger D.R. \& Wyatt R.J. (1979). Anomalous lateralization associated with a milder form of schizophrenia. American Journal of Psychiatry 136, 1598-1599.

Luchins D.J., Weinberger D.R. \& Wyatt R.J. (1982). Schizophrenia and cerebral asymmetry detected by computed tomography. American Journal of Psychiatry 139, 753-757.

Maier W. \& Schwab S. (1998). Molecular genetics of schizophrenia. Current Opinion in Psychiatry 11, 19-25.

McGrath J. \& Murray R.M. (1995). Risk factors for schizophre- 
nia: from conception to birth. In Schizophrenia (ed. S.Hirsh and D.Weinberger), pp187-205. Blackwell: Oxford.

McGuire P.K., Shah G.M. \& Murray R.M. (1993). Increased blood flow in Broca's area during auditory hallucinations in schizophrenia. Lancet 342, 703-706.

McGuire P.K., Jones P., Harvey I., Bebbington P., Toone B., Lewis S. \& Murray R.M. (1994). Cannabis and acute psychosis. Schizophrenia Research 13, 161-167.

McKenzie K. \& Murray R.M. (submitted for publication). Evidence for low rates of neurological risk factors in African-Caribbean patients with psychosis in the UK compared to White patients

McNeil T.F. (1995). Perinatal risk factors and schizophrenia: selective review and methodological concerns. Epidemiologic Reviews $17,107-112$

Mortensen P.B., Pedersen C.B., Westergaard T., Wohlfahrt J., Ewald H., Mors O., Andersen P.K. \& Melbye M. (1999). Effects of family history and place and season of birth on the risk of schizophrenia. New England Journal of Medicine 340, 603-608.

Murray R.M. (1994). Neurodevelopmental schizophrenia: the rediscovery of dementia praecox. British Journal of Psychiatry 165, suppl. 25, 6-12.

Murray R.M. \& McGuffin P. (1993). Genetic aspects of psychiatric disorders. In Companion to Psychiatric studies (ed. R.E. Kendell and A.K. Zealley), pp 227-261. Churchill-Livingstone: Edinburgh.

Murray R.M., Lewis S.W. \& Reveley, A.M. (1985). Towards an aetiological classification of schizophrenia. Lancet 1, 10231026.

Murray R.M., O'Callaghan E., Castle D.J. \& Lewis S.W. (1992). A neurodevelopmental approach to the classification of schizophrenia. Schizophrenia Bulletin 18, 319-332.

Orr K.G.D., Cannon M., Gilvarry C.M., Jones P.B. \& Murray R.M. (in press). Schizophrenic patients and their first degree relatives show an excess of mixed handedness. Schizophrenia Research 39, 167-176.

Rifkin L., Lewis S., Jones P.B., Toone B.K. \& Murray R.M. (1994). Schizophrenic patients of low birth weight show poor premorbid function, and cognitive impairment in adult life. British Journal of Psychiatry 165, 357-362.

Saykin A.J., Gur R.C., Gur R.E., Mozley P.D., Mozley L.H., Resnick S.M., Kester D.B. \& Stafiniak P. (1991). Neuropsychological function in schizophrenia: selective impairment in memory and learning. Archives of General Psychiatry 48, 618-624.

Saykin A.J., Shtasel D.L., Gur R.E., Kester D.B., Mozley L.H., Stafiniak P. \& Gur R.C. (1994). Neuropsychological deficits in neuroleptic-naïve patients with first-episode schizophrenia. Archives of General Psychiatry 51, 124-131.

Sham P.C., O'Callaghan E., Takei N., Murray G.K., Hare E.H. \& Murray R.M. (1992). Schizophrenia following prenatal exposure to influenza epidemics between 1939 and 1960. British Journal of Psychiatry 160, 461-466.
Shapleske J., Rossell S.L., Woodruff P.W.R. \& David A.S (1999). The planum temporale: a systematic, quantitative review of its structural, functional and clinical significance. Brain Research Reviews 29, 26-49.

Sharma T., Lancaster E., Lee D., Lewis S., Sigmundsson T., Takei N., Gurling H., Barta P., Pearlson G. \& Murray R. (1998). Volumetric MRI study of families multiply affected with schizophrenia the Maudsley Family Study 5. British Journal of Psychiatry 173, 132-138.

Sharma T., Lancaster E., Sigmundsson T., Lewis S., Noriyoshi T., Gurling H., Barta P., Pearlson G. \& Murray R.M. (in press). Lack of normal pattern of cerebral asymmetry familial schizophrenics patients and their relatives: the Maudsley Family Study. Schizophrenia Bulletin.

Stefanis N., Frangou S., Yakeley J., Sharma T., O'Connell P., Morgan K., Sigmundsson T., Taylor M. \& Murray R.M. (1999). Hippocampal volume reduction: effects of genetic risk and pregnancy and birth complications. British Journal of Psychiatry, 46, 697-702.

Straub R.E., MacLean C.J., O'Neil F.A., Burke J., Murphy B., Duke F., Shinkwin R., Webb B.T., Zhang J., Walsh D. \& Kendler K.S. (1995). A potential variability locus for schizophrenia on chromosome 6p24-22: evidence for genetic heterogeneity. Nature Genetics 11, 287-293.

Suddath R.I., Christison G.W. \& Torrey E.F. (1990). Anatomical abnormalities in the brains of monozygotic twins discordant for schizophrenia. New England Journal of Medicine 322, 789-794.

Torrey E.F. \& Bowler A. (1990). Geografical distribution of insanity in America: evidence for an urban factor. Schizophrenia Bulletin 16, 591-604.

Torrey E.F., Miller J., Rawlings R. \& Yolken R.H. (1997). Seasonality of births in schizophrenia and bipolar disorder: a review of the literature (abstract). Schizophrenia Research 24, 260.

Van Os J. \& Murray R.M. (submitted for publication). Neurodevelopmental and social risk factors across the continuum of psychosis.

Van Os J., Marcelis M., Sham P., Jones P., Gilvarry K. \& Murray R. (1998). Psychopathological syndromes and familial morbid risk of psychosis. British Journal of Psychiatry 170, 241-246.

Verdoux H., Geddes J.R., Takei N., Lawrie S.M., Bovet P., Eagles J.M., Heun R., McCreadie R.G., McNeil T.F., O'Callaghan E., Stober G., Willinger U., Wright R. \& Murray R.M. (1997). Obstetric complications and age at onset in schizophrenia: An international collaborative meta-analysis of individual patient data. American Journal of Psychiatry 154, 1220-1227.

Wessely S., Castle D., Der G. \& Murray R.M.(1991). Schizophrenia and Afro-Caribbeans. A case-control study. British Journal of Psychiatry 159, 795-801.

Wickham H. \& Murray R.M. (1997). Can biological markers identify endophenotypes predisposing to schizophrenia? International Review of Psychiatry 9, 355-364. 